\title{
Removal of Refractory Organics from Biologically Treated Landfill Leachate by Microwave Discharge Electrodeless Lamp Assisted Fenton Process
}

\author{
Jiuyi Li, ${ }^{1}$ Lele Qin, ${ }^{1}$ Lei Zhao, ${ }^{1}$ Aimin Wang, ${ }^{1}$ Yong Chen, ${ }^{2}$ Liao Meng, \\ Zhongguo Zhang, ${ }^{4}$ Xiujun Tian, ${ }^{1}$ and Yanmei Zhou ${ }^{1}$ \\ ${ }^{1}$ Department of Civil and Environmental Engineering, Beijing Key Laboratory of Aqueous Typical Pollutants Control and \\ Water Quality Safeguard, School of Civil Engineering, Beijing Jiaotong University, Beijing 100044, China \\ ${ }^{2}$ China Construction Technology Consulting Co. LTD, Beijing 100120, China \\ ${ }^{3}$ Xiaping Municipal Solid Waste Landfill Plant, Shenzhen, Guangdong 518000, China \\ ${ }^{4}$ Environmental Protection Research Institute of Light Industry, Beijing Academy of Science and Technology, Beijing 100089, China
}

Correspondence should be addressed to Xiujun Tian; xjtian@bjtu.edu.cn

Received 24 October 2015; Accepted 30 November 2015

Academic Editor: Leonardo Palmisano

Copyright (C) 2015 Jiuyi Li et al. This is an open access article distributed under the Creative Commons Attribution License, which permits unrestricted use, distribution, and reproduction in any medium, provided the original work is properly cited.

\begin{abstract}
Biologically treated leachate usually contains considerable amount of refractory organics and trace concentrations of xenobiotic pollutants. Removal of refractory organics from biologically treated landfill leachate by a novel microwave discharge electrodeless lamp (MDEL) assisted Fenton process was investigated in the present study in comparison to conventional Fenton and ultraviolet Fenton processes. Conventional Fenton and ultraviolet Fenton processes could substantially remove up to $70 \%$ of the refractory organics in a membrane bioreactor treated leachate. MDEL assisted Fenton process achieved excellent removal performance of the refractory components, and the effluent chemical oxygen demand concentration was lower than $100 \mathrm{mg} \mathrm{L}^{-1}$. Most organic matters were transformed into smaller compounds with molecular weights less than $1000 \mathrm{Da}$. Ten different polycyclic aromatic hydrocarbons were detected in the biologically treated leachate, most of which were effectively removed by MDEL-Fenton treatment. MDEL-Fenton process provides powerful capability in degradation of refractory and xenobiotic organic pollutants in landfill leachate and could be adopted as a single-stage polishing process for biologically treated landfill leachate to meet the stringent discharge limit.
\end{abstract}

\section{Introduction}

The disposal of municipal solid wastes in landfill is a common practice in both developed and developing countries due to technological maturity and economic advantage even though the generation of landfill leachate is an important drawback $[1,2]$. Landfill leachate is strongly polluted wastewater that contains a large variety of different compounds, some of which can be expected to create a threat to health and nature if released into the natural environment [3-6]. Biological treatment systems have been extensively employed to remove the biodegradable contaminants in landfill leachates. However, most biological treatment processes are not efficient enough to conform to the legislations for discharge into water bodies, for instance, the discharge regulation guidelines for municipal solid waste landfill leachate (GB16889-2008) in China.

The biologically treated leachates contain significant amount of biorefractory organic matters, such as fulvic and humic-like compounds $[7,8]$, with chemical oxygen demands (COD) up to several hundred milligrams per liter. Moreover, many hazardous compounds, including halogenated aliphatic compounds and polycyclic aromatic hydrocarbons (PAHs), have been detected at very low concentrations in leachates. Low concentrations do not eliminate environmental threats, as many compounds can be assumed to be hazardous even in small amounts and negative effects are often caused by multiple and synergistic effects. Thus, 
TABLE 1: Water quality of biologically treated landfill leachate used in the study.

\begin{tabular}{lcccccc}
\hline Parameters & $\mathrm{pH}$ & $\begin{array}{c}\mathrm{COD} \\
\left(\mathrm{mg} \mathrm{L}^{-1}\right)\end{array}$ & $\begin{array}{c}\mathrm{TOC} \\
\left(\mathrm{mg} \mathrm{L}^{-1}\right)\end{array}$ & $\begin{array}{c}\mathrm{TDS} \\
\left(\mathrm{mg} \mathrm{L}^{-1}\right)\end{array}$ & $\begin{array}{c}\mathrm{Cl}^{-} \\
\left(\mathrm{mg} \mathrm{L}^{-1}\right)\end{array}$ & $\begin{array}{c}\mathrm{BOD}_{5} \\
\left(\mathrm{mg} \mathrm{L}^{-1}\right)\end{array}$ \\
\hline Values & 8.3 & 590 & 203 & 292370 & 4600 \\
\hline Parameters & $\begin{array}{c}\mathrm{TN} \\
\left(\mathrm{m} \mathrm{L} \mathrm{L}^{-1}\right)\end{array}$ & $\begin{array}{c}\mathrm{NH}_{4}^{+}-\mathrm{N} \\
\left(\mathrm{mg} \mathrm{L}^{-1}\right)\end{array}$ & $\begin{array}{c}\mathrm{NO}_{2}^{-}-\mathrm{N} \\
\left(\mathrm{mg} \mathrm{L}^{-1}\right)\end{array}$ & $\begin{array}{c}\mathrm{NO}_{3}^{-}-\mathrm{N} \\
\left(\mathrm{mg} \mathrm{L}^{-1}\right)\end{array}$ & $\begin{array}{c}\mathrm{PO}_{4}^{3-}-\mathrm{P}^{3} \\
\left(\mathrm{mg} \mathrm{L}^{-1}\right)\end{array}$ & $\begin{array}{c}\mathrm{UV}_{254}\left(\mathrm{~cm}^{-1}\right) \\
\text { diluted } 1: 20\end{array}$ \\
\hline Values & 51.5 & 2.3 & 0.1 & 48.8 & 16.8 \\
\hline
\end{tabular}

physicochemical oxidation processes are needed to gain better removal performance for both high amounts of refractory organic matters and trace concentration of xenobiotic pollutants in biologically treated leachate.

Fenton and photo assisted Fenton processes have attracted intensive interest in the landfill leachate treatments due to their advanced capability in oxidation of refractory organic compounds, moderate cost, and simplicity of operation [7, 9-12]. In Fenton process, highly reactive hydroxyl radicals $\left({ }^{\circ} \mathrm{OH}\right)$, whose oxidation potential is 2.70 electron volts, only lower than fluorine, are generated in the catalytic decomposition of hydrogen peroxide by ferrous ion. It is reported that around $60-85 \%$ of COD removal in biologically treated landfill leachates can be accomplished under the optimal reactive agent dosage conditions. Photo assisted Fenton process is based on the same reagents as Fenton process but the solution is additionally exposed to ultraviolet radiations (UV-Fenton), which results in higher generation of hydroxyl radicals. Generally, UV-Fenton could significantly reduce dosage of ferrous ion and improve COD removal efficiency depending on the landfill leachate characteristics, reagent dosages, and photoirradiation.

Recently, microwave discharge electrodeless lamps (MDELs) have been used to substitute traditional Hg lamps in photocatalysis treatment of various gaseous and aqueous pollutants [13-17]. A MDEL comprises an envelope or bulb containing a plasma-forming medium. When the MDEL is placed in a microwave energy field, the gases within the envelope ionize and a low-pressure plasma discharge forms, beating the envelope, vaporizing materials to emit light. Compared with normal UV light sources, MDELs do not produce blackened electrodes caused by wear and tear, oxidation, and sealing due to the absence of electrodes. In addition, MDELs have many advantages such as their low price, low energy cost, high light intensity, and simple reactor. Moreover, there are many options for light-emitting materials so that MDELs can provide different wavelengths of UV radiation $[18,19]$. MDEL is a promising technology for photo assisted Fenton process to degrade the recalcitrant matters in landfill leachate, but the removal performance is still unclear so far.

The aims of the present work are twofold: (1) to develop a single-stage treatment technology to remove the high concentrations of refractory organic matters in biologically treated landfill leachate by using Fenton, UV-Fenton, and MDEL-Fenton oxidation processes in order to meet the discharge regulations and (2) to quantify the changes of the trace PAHs during the various Fenton-based treatment processes.

\section{Materials and Methods}

2.1. Materials. Leachate samples from a landfill in Shenzhen (China) taken between February and June 2014 were used in the study. Leachates were collected from the outlet of a membrane bioreactor (MBR) that follows an air-stripper tower for ammonia removal. The MBR consists of an anoxic and aerobic tank in sequence, and the mixed liquor in the aerobic tank is recycled into the anoxic tank. Six hollow fiber microfiltration membrane modules with a pore size of $0.1 \mu \mathrm{m}$ were used to separate the activated sludge from the MBR effluent. After sampling, the leachate was preserved in a refrigerator protected from light. The water main characteristics of the biologically treated leachate are listed in Table 1.

All chemicals used in Fenton and MDEL-Fenton experiments were of analytical grade and were supplied by Sinopharm Chemical Reagent Co. (Beijing, China). The calibration mixture of 25 PAHs, including tetrahydronaphthalene, beta-chloronaphthalene, indene, naphthalene, 2-methylnaphthalene, 1-methylnaphthalene, acenaphthylene, acenaphthene, fluorene, dibenzothiophene, phenanthrene, anthracene, retene, fluoranthene pyrene, benzo[a]anthracene, chrysene, benzo[b]fluoranthene, benzo[k]fluoranthene, benzo[e]pyrene, benzo[a]pyrene, perylene, dibenz[a, $\mathrm{h}]$ anthracene, benzo[g,h,i]perylene, and indeno[1,2,3-c, d]pyrene, was purchased from Supelco, USA, with each component in methanol: methylene chloride $(50: 50, \mathrm{~V} / \mathrm{V})$. Phenanthrene-D10 and acenaphthylene-D10 (Supelco, USA) were used as surrogates to quantify PAHs recoveries.

2.2. Experimental Set-Up. The Fenton experiments were performed in a batch mode reactor with an effective volume of $200 \mathrm{~mL}$. The leachate was mixed throughout the experiment with a magnetic device. The operational $\mathrm{pH}$ and reagent concentrations were optimized. The initial $\mathrm{pH}$ was adjusted to the desired value using $1 \mathrm{~mol} \mathrm{~L}^{-1}$ sulfuric acid. Ferrous sulfate was added to reach the targeted ferrous ion concentration. Hydrogen peroxide was then added in batch mode until the designated concentration was reached. After $1 \mathrm{~h}$ of reaction, aliquots of treated leachate were taken with a syringe and filtered through a $0.45 \mu \mathrm{m}$ filter membrane to collect the filtrate for the analysis of residual organic matter.

UV-Fenton treatments were carried out in a cylindershaped batch reactor with an effective volume of $600 \mathrm{~mL}$. UV irradiation with a wavelength of $254 \mathrm{~nm}$ was provided by a $10 \mathrm{~W}$ high-pressure mercury lamp. The lamp was inserted into a quartz glass sheath and immersed into the center of the reactor. When applying the UV-Fenton process, all experimental procedures were the same as the Fenton, except that 


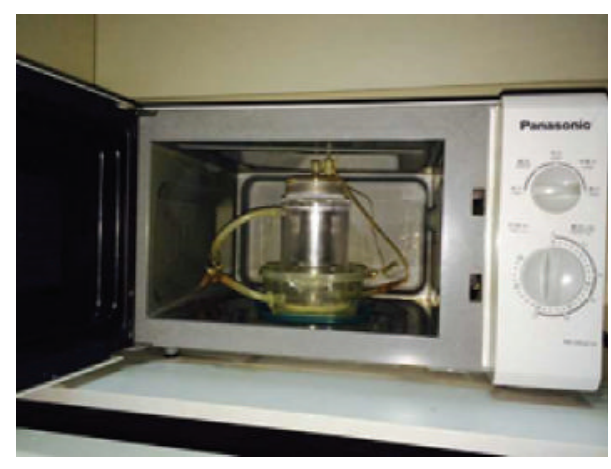

(a)

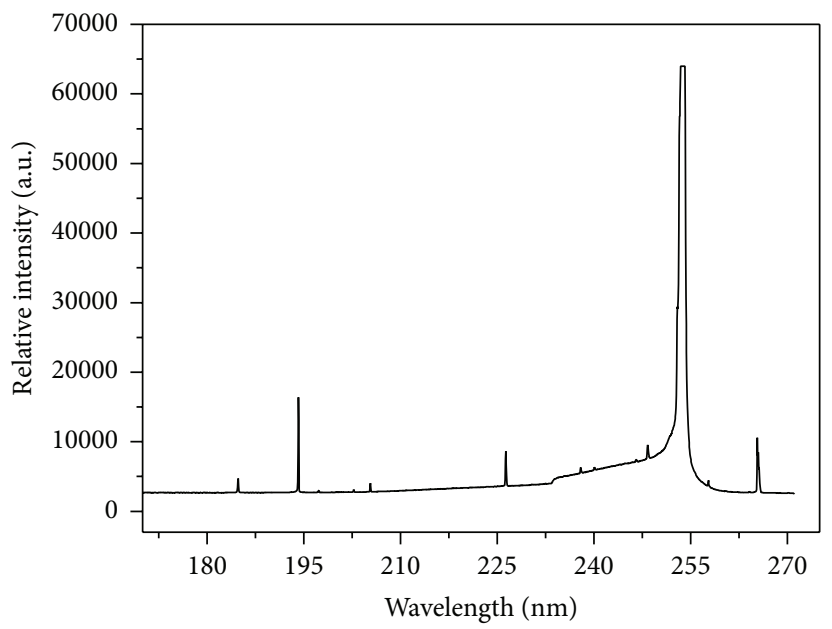

(d)

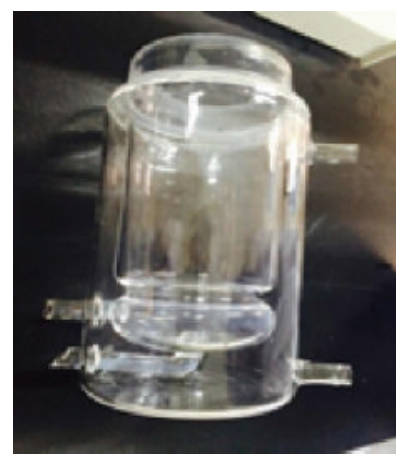

(b)

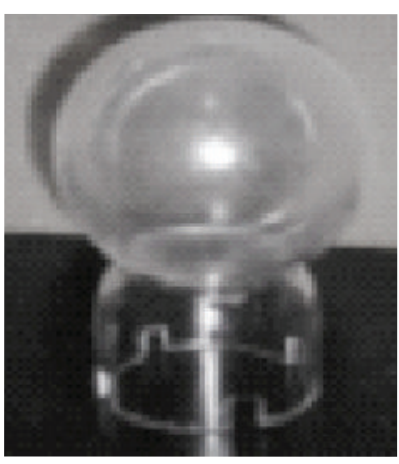

(c)

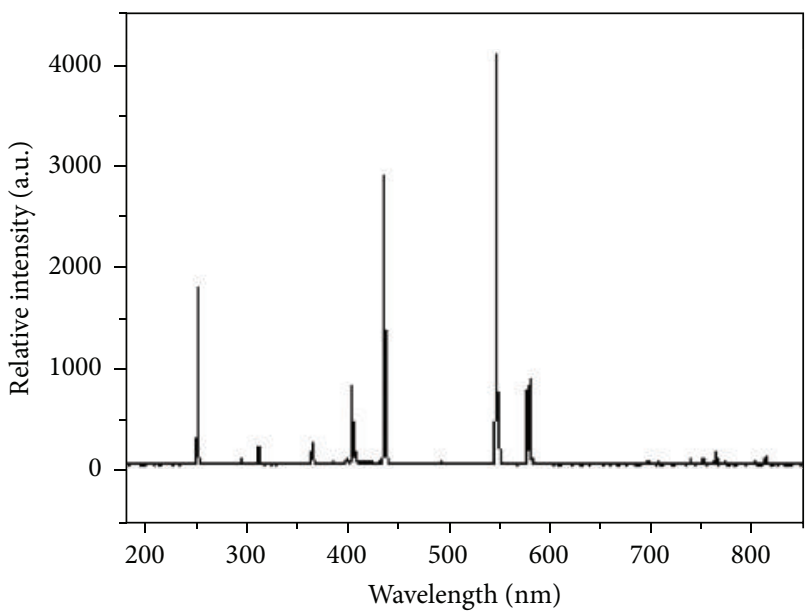

(e)

FIGURE 1: (a) Photograph of the microwave discharge electrodeless lamp (MDEL) assisted Fenton system, (b) reactor, and (c) MDEL. (d) and (e) Emission spectra of the MDEL.

the UV lamp was switched on simultaneously as hydrogen peroxide was added.

The MDEL-Fenton treatment was conducted in a homemade undivided reactor, as illustrated in Figure 1(a), containing $250 \mathrm{~mL}$ of the leachate. The microwave source was a domestic microwave oven (Panasonic Co., Japan; power, $700 \mathrm{~W}$; frequency, $2.45 \mathrm{GHz}$ ), and the microwave was maintained continuously during the treatment. The MDEL-Fenton reactor was a double-wall cylindrical quartz reactor equipped with water-cooling apparatus (Figure 1(b)). Solution temperature was kept at $30 \pm 1^{\circ} \mathrm{C}$. A spherical MDEL with a diameter of $6 \mathrm{~cm}$ made of quartz and filled with $20 \mathrm{mg}$ mercury and 5.0 Torr argon was manufactured by the university workshop (Figure 1(c)). The UV-Vis radiations emitted by the light source of the MDEL are depicted in Figures 1(d) and 1(e). The peaks in the emission spectrum of MDEL appeared at 185, 193, $226,254,264,295,313,366,404,436,546$, and $581 \mathrm{~nm}$. The MDEL floated on the solution and about $80 \%$ was immerged in the leachate during the treatment. During MDEL-Fenton process, air was introduced into the solution at a flow rate of $0.6 \mathrm{~L} \mathrm{~min}^{-1}$ to supply oxygen and mix the solution constantly.

2.3. Molecular Weight Fractionation of Organic Matters in Leachate. The molecular weight fractionation of the organic matters in raw and treated leachate samples were determined by ultrafiltration assays. Ultrafiltration of leachate samples was conducted using a dead end batch $200 \mathrm{~mL}$ stirred ultrafiltration apparatus (Model 8200, Amicon, Belford, MA, USA), a nitrogen gas tank (pressure: $120 \mathrm{kPa}$ ), and membrane discs with the molecular weight cut-offs of 1,5 , and $10 \mathrm{kDa}$ (Millipore, Billerica, MA, USA).

2.4. Extraction Process for PAHs in Leachates. The leachate samples before and after different treatments were spiked with surrogates before extraction. $500 \mathrm{~mL}$ of each leachate sample was extracted with a $6 \mathrm{~mL}(0.5 \mathrm{~g})$ Supelclean ENVI-18 SPE cartridge (Supelco, USA) and a $6 \mathrm{~mL}(0.5 \mathrm{~g})$ Oasis HLB LP cartridge (Waters Corp., USA) in serial at a flow rate of $6 \mathrm{~mL} \mathrm{~min}^{-1}$. The cartridges were prewashed with $10 \mathrm{~mL}$ of acetone and conditioned with $10 \mathrm{~mL}$ of methanol followed by $10 \mathrm{~mL}$ of ultrapure water. After extraction, the HLB cartridge was eluted using $10 \mathrm{~mL}$ acetone : methanol mixture $(90: 10, \mathrm{~V} / \mathrm{V})$, while the SPE cartridge was eluted using $10 \mathrm{~mL}$ hexane:acetone mixture $(70: 30, \mathrm{~V} / \mathrm{V})$. All extracts were evaporated to near dryness under a gentle flow of nitrogen gas and dissolved in $1 \mathrm{~mL}$ of hexane and added with the internal standards. 
2.5. Analysis. COD was determined according to the Standard Methods [20]. Dissolved organic carbon (DOC) was measured using high temperature combustion with a TOC analyzer (Shimadzu TOC-5000A, Japan). The UV-Vis absorbance in the range from $\lambda=200 \mathrm{~nm}$ to $\lambda=600 \mathrm{~nm}$ was analyzed via UV-1800 UV-Vis spectrophotometer (Shimadzu Co., Japan), equipped with a quartz cell with a path length of $1 \mathrm{~cm}$. The absorbance parameters $\mathrm{UV}_{254}$ and $\mathrm{CO}_{436}$ of samples were also determined.

PAHs were analyzed by a Bruker 451 gas chromatograph connected to a mass spectrometry (GC/MS) using anthracene-D10 as internal standard. GC was equipped with a capillary column (DB-5MS, $30 \mathrm{~m} \times 0.25 \mathrm{~mm} \times 0.25 \mu \mathrm{m}$, Agilent, USA) and sample size was $1.0 \mu \mathrm{L}$ (nonflow injection). Carrier gas was $\mathrm{He}$ (purity 99.99\%) and flow rate was $1 \mathrm{~mL} \mathrm{~min}{ }^{-1}$. The temperature of introduction port was $280^{\circ} \mathrm{C}$ and detector was $300^{\circ} \mathrm{C}$. The start temperature of column was $40^{\circ} \mathrm{C}$, stayed for $2 \mathrm{~min}$, temperature programmed up to $300^{\circ} \mathrm{C}$ by the rate of $5^{\circ} \mathrm{C} \mathrm{min}{ }^{-1}$ and then stayed for $5 \mathrm{~min}$. SIM scan was selected. The determination condition of MS was as follows: ion source (EI) temperature of $270^{\circ} \mathrm{C}$, quadrupole temperature of $200^{\circ} \mathrm{C}$, and EI voltage of $70 \mathrm{eV}$. The concentrations of organic compounds were calculated using standard curve. Surrogate recoveries for all samples were above 69\% for both phenanthrene-D10 and acenaphthylene-D10.

\section{Results and Discussion}

3.1. Removal Performance of Refractory Organic Matters. The optimal operational conditions for conventional Fenton, UVFenton, and MDEL assisted Fenton processes were determined on the basis of COD, TOC, and $\mathrm{UV}_{254}$ absorbance removal performance. Figure 2 shows the influence of initial $\mathrm{pH}$ in convention Fenton process. Results indicated that initial $\mathrm{pH}$ significantly influenced COD removal since $\mathrm{pH}$ controls the activity of the oxidant and the stability of hydrogen peroxide [10]. As shown in Figure 2, the COD removal could be higher than $60 \%$ within the $\mathrm{pH}$ from 3.0 to 6.0 with $\mathrm{Fe}^{2+}$ and $\mathrm{H}_{2} \mathrm{O}_{2}$ dosage of 3 and $20 \mathrm{mM}$, respectively, while the optimal initial pH of 5.0 is established. Even though this result does not agree with many previous findings $(\mathrm{pH}<$ 4) $[7,10,11]$, the $\mathrm{pH}$ titration curves of the leachate indicate that the major capacity of alkalinity falls into the $\mathrm{pH}$ range 5 to 7 and the aqueous $\mathrm{pH}$ decreased rapidly to around 3 during the Fenton treatment (data not shown).

Figure 3 shows the effects of hydrogen peroxide concentration on the COD, TOC, and $\mathrm{UV}_{254}$ removal at various ferrous ion concentrations in Fenton process. Visible iron precipitates were formed after ferrous sulfate addition into the leachate, and about 6-9\% COD removal can be achieved without hydrogen peroxide addition. Best removal performance of organic matter was obtained with $\mathrm{Fe}^{2+}$ concentration of $2 \mathrm{mM}$, and the COD removal efficiencies were higher than $70 \%$, and the remaining COD ranged from 130 to $180 \mathrm{mg} \mathrm{L}^{-1}$. A lower dosage of $\mathrm{Fe}^{2+}(1 \mathrm{mM})$ resulted in COD removal less than $50 \%$. Unexpectedly, higher $\mathrm{Fe}^{2+}$ dosage did not gain further COD removal but led to excessive production of iron sludge that should be disposed of.

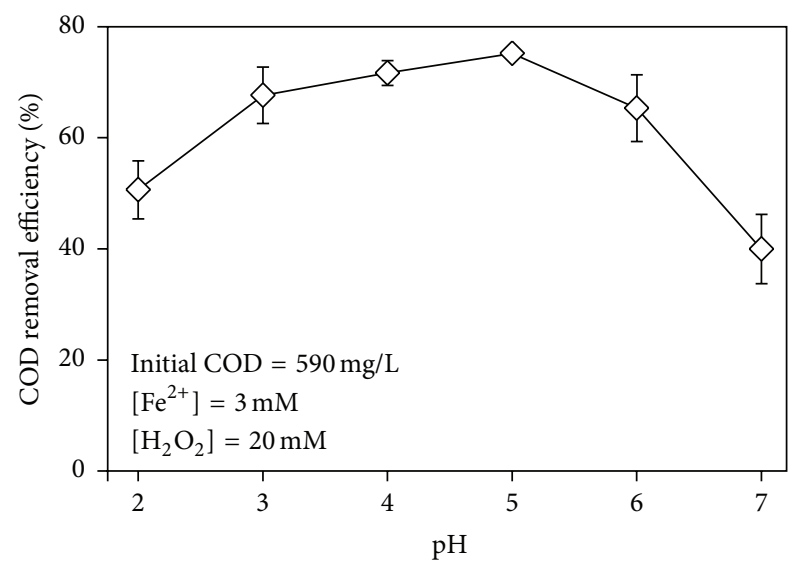

FIgURE 2: Effect of initial $\mathrm{pH}$ on COD removal in the treatment of landfill leachate by conventional Fenton process.

With a dosage of $2 \mathrm{mM} \mathrm{Fe}{ }^{2+}$, COD removal efficiency increased rapidly to around $70 \%$ at a dosage of $6 \mathrm{mM} \mathrm{H}_{2} \mathrm{O}_{2}$, that is, $\left[\mathrm{H}_{2} \mathrm{O}_{2} / \mathrm{Fe}^{2+}\right]=3$, and increased much slower up to $78 \%$ upon further increases of $\mathrm{H}_{2} \mathrm{O}_{2}$ concentration. Further addition of $\mathrm{H}_{2} \mathrm{O}_{2}$ did not result in significant difference in COD removal due to the slow mineralization of highly refractory organic compounds and the reduction of $\mathrm{Fe}^{3+}$ to $\mathrm{Fe}^{2+}$ with the generation of hydroxyl radicals [7]. Harber and Weiss [21] reported that Fenton reaction was second order with respect to hydrogen peroxide and ferrous ion at low $\left[\mathrm{H}_{2} \mathrm{O}_{2} / \mathrm{Fe}^{2+}\right]$ but became zero order at high $\left[\mathrm{H}_{2} \mathrm{O}_{2} / \mathrm{Fe}^{2+}\right]$.

Fenton process could effectively remove the refractory organic matters present in the biologically treated leachate at low reactive agent levels. $\mathrm{H}_{2} \mathrm{O}_{2}$ consumption per unit mass of COD removed is $0.48 \mathrm{mg} \mathrm{H}_{2} \mathrm{O}_{2} \mathrm{mg}^{-1} \mathrm{COD}$, which is much less than those reported previously [22]. However, the remaining COD in the effluent of Fenton oxidation is still higher than the discharge limit of $100 \mathrm{mg} \mathrm{L}^{-1}$.

Figure 4 shows the influence of $\mathrm{Fe}^{2+}$ and $\mathrm{H}_{2} \mathrm{O}_{2}$ dosages on the removal performance of COD and TOC in leachate via UV-Fenton oxidation. Reduction of organic matters by UV-Fenton process followed the similar trend with conventional Fenton treatment. Rapid reduction of COD was easily obtained at low $\mathrm{H}_{2} \mathrm{O}_{2}$ dosages, while further removal was comparatively difficult to be accomplished. With the aid of UV irradiations, higher amount of recalcitrant organic matters was mineralized at the conditions of ferrous ion concentration of $3 \mathrm{mM}$.

MDEL-Fenton experiments were performed at different $\mathrm{Fe}^{2+}$ and $\mathrm{H}_{2} \mathrm{O}_{2}$ concentrations, and the results are present in Figure 5. With the aid of MDEL irradiations, COD removal of $10-20 \%$ could be obtained by iron precipitation alone without $\mathrm{H}_{2} \mathrm{O}_{2}$ addition. Ferrous ion affected the removal of COD significantly. Under the experimental condition of $0.5 \mathrm{mM}$ $\mathrm{Fe}^{2+}$, the COD removal efficiencies increased linearly up to $42 \%$ with the addition of $12 \mathrm{mM} \mathrm{H}_{2} \mathrm{O}_{2}$, and the efficiency increased in a much lower trend and leveled off at 55\% COD removal with higher dosage of $\mathrm{H}_{2} \mathrm{O}_{2}$. At higher concentrations of ferrous ion, COD removal increased gradually with the increasing dosage of $\mathrm{H}_{2} \mathrm{O}_{2}$. COD removal efficiency 


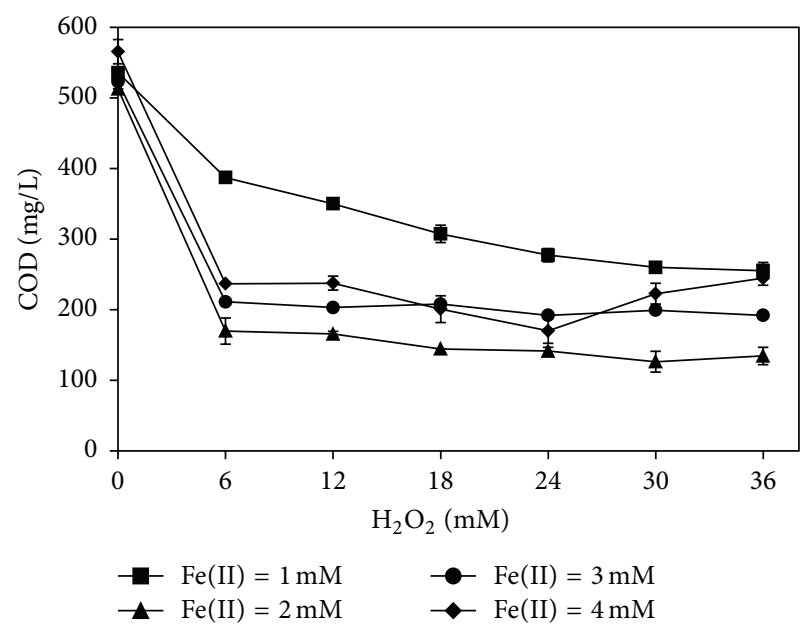

(a)

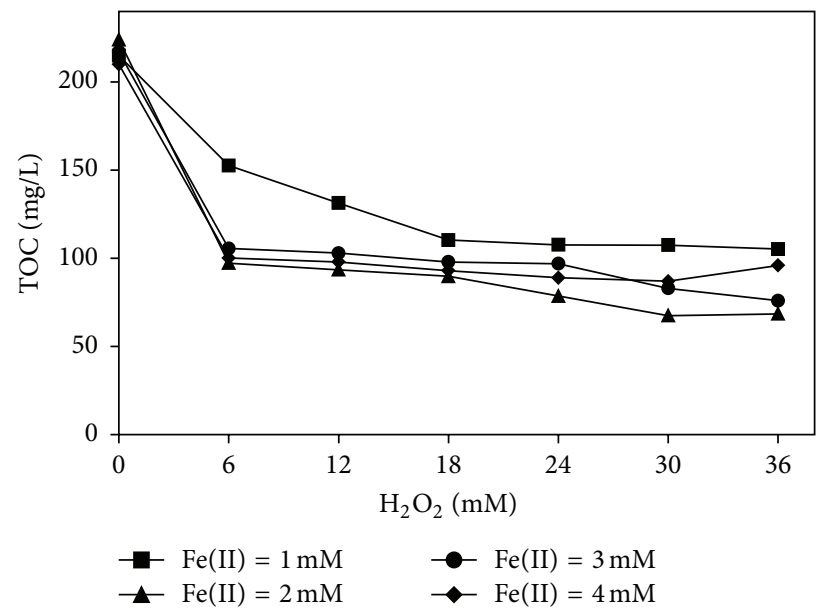

(b)

FIGURE 3: Effects of $\mathrm{Fe}(\mathrm{II})$ and $\mathrm{H}_{2} \mathrm{O}_{2}$ dosages on COD (a) and TOC (b) removal in membrane bioreactor leachate effluent by conventional Fenton process.

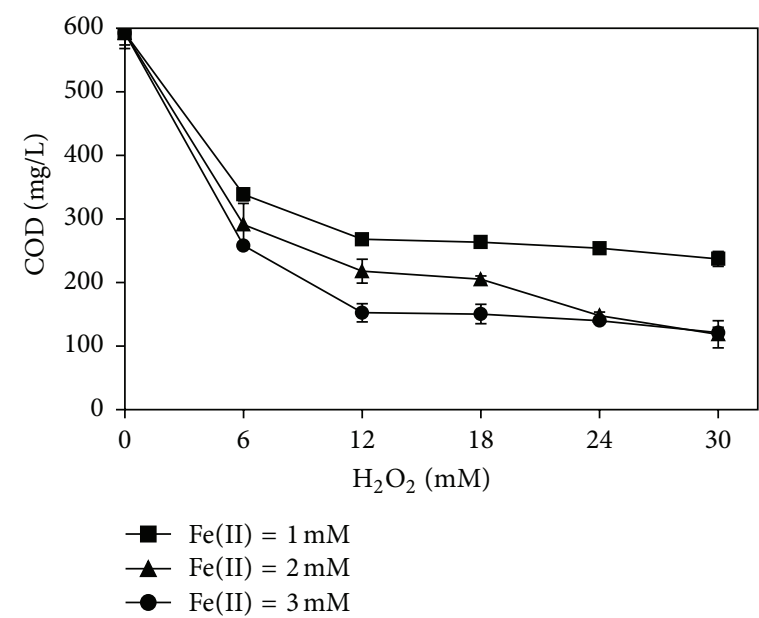

(a)

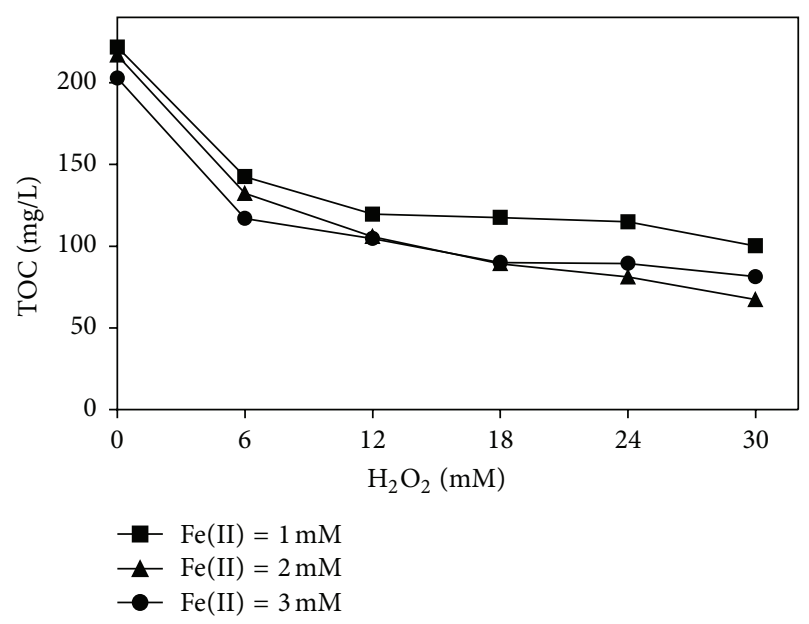

(b)

FIGURE 4: Effects of reaction reagents on COD (a) and TOC (b) removal in MBR leachate effluent by ultraviolet Fenton process.

higher than $83 \%$ and effluent COD less than $100 \mathrm{mg} \mathrm{L}^{-1}$ could be achieved at $\mathrm{Fe}^{2+}$ and $\mathrm{H}_{2} \mathrm{O}_{2}$ dosages of $2 \mathrm{mM}$ and $47 \mathrm{mM}$, respectively. The COD in effluent of MDEL-Fenton process was $87 \pm 5 \mathrm{mg} \mathrm{L}^{-1}$ with $\mathrm{H}_{2} \mathrm{O}_{2}$ dosage of $52 \mathrm{mM}$ and was consistently lower than the discharge limit. In comparison to the Fenton process, the introduction of MDEL irradiation did not improve COD removal at low $\mathrm{H}_{2} \mathrm{O}_{2}$ concentrations, for example, $12 \mathrm{mM}$, while MDEL irradiation gradually increased COD removal efficiency with further increment of $\mathrm{H}_{2} \mathrm{O}_{2}$ addition, albeit in a much lower trend. Moreover, we could conclude that the optimal $\mathrm{Fe}^{2+}$ concentration in MDELFenton oxidation is much less than conventional Fenton. As a result, a great variety of ferric complexes are formed and the amount of ferric ions in MDEL-Fenton oxidation is reduced [10]. Owing to lower $\mathrm{Fe}^{2+}$ dosage in MDEL-Fenton process, much less precipitate was formed and most refractory organic compounds were mineralized by the oxidative reagents added and formed in the aqueous solution, which may partially account for the higher $\mathrm{H}_{2} \mathrm{O}_{2}$ concentration for COD removal.

Excellent COD removal performance in MDEL-Fenton process provides an alternative option for polishing the recalcitrant organics in biologically treated landfill leachate. Currently, most Chinese landfill plants use nanofiltration and/or reverse osmosis processes to separate the refractory organic compounds, which requires huge capital investment and operating costs. These membrane-based processes produce concentrated brine that contains nearly all refractory organic matters in the leachate. Unfortunately, mineralization of these compounds by physicochemical oxidation process is inevitable.

3.2. Transformation Characterization of Refractory Organics. The UV-Vis absorbance spectra of the refractory organic matters show an increase in the absorbance with the decreasing 


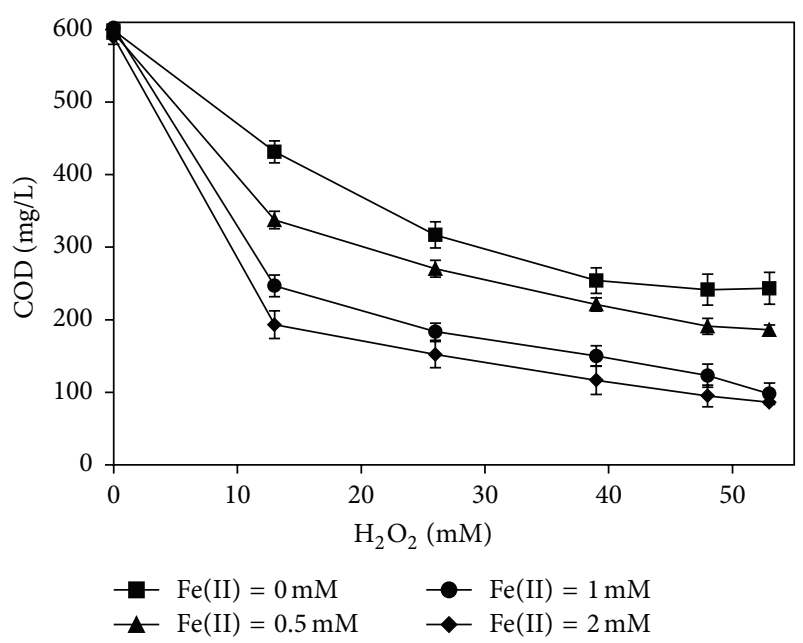

(a)

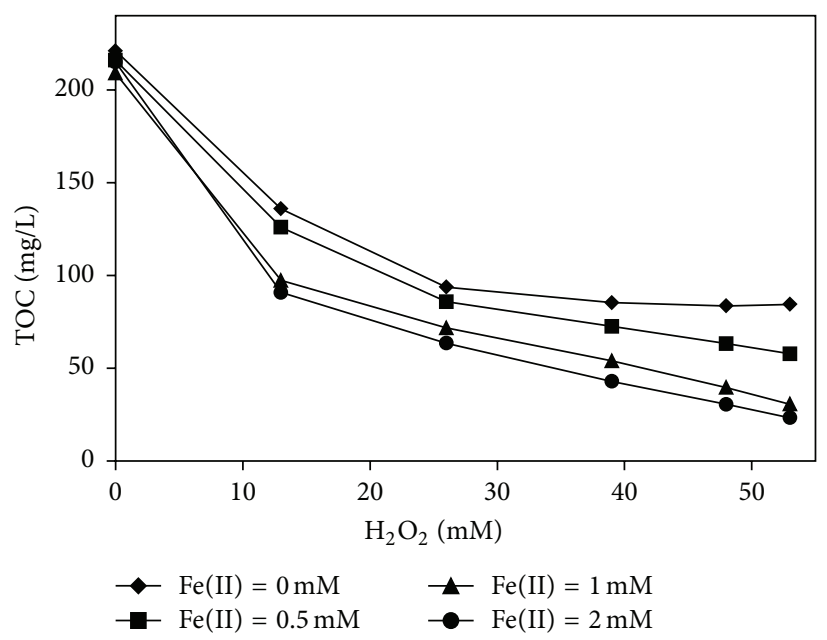

(b)

FIGURE 5: Leachate COD (a) and TOC (b) removal performance using microwave discharge electrodeless lamp assisted Fenton process as a function of reactive reagent dosages.

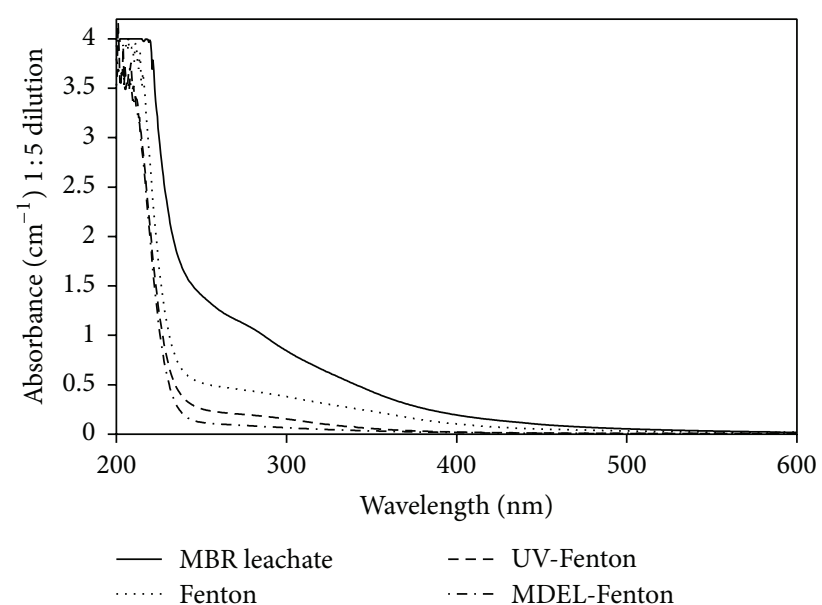

FIGURE 6: Changes of UV-Vis absorbance spectra of leachate with Fenton and microwave discharge electrodeless lamp assisted Fenton processes. All samples were diluted 1:5.

wavelength (Figure 6). With Fenton and MDEL-Fenton oxidation, a steady decrease in the UV-Vis absorption was observed. For example, $\mathrm{UV}_{254}$ has been shown to be a useful parameter for estimating the dissolved aromatic carbon content in aquatic systems, and the $254 \mathrm{~nm}$ absorbance is linked to organic compounds with one or many double bonds. $\mathrm{UV}_{254}$ absorbance of leachate was largely reduced from 1.35 to $0.5,0.24$, and 0.11 after Fenton, UV-Fenton, and MDEL-Fenton oxidation, respectively.

A comparison of the TOC distribution among the organic substances of different MW was performed. As shown in Figure 7(a), the component with MWs less than $1 \mathrm{kDa}$ contributed to around 50 percent in the biologically treated leachate, and the rest of organic components were nearly evenly distributed in the MW range among $1-5 \mathrm{kDa}$, 5$10 \mathrm{kDa}$, and $>10 \mathrm{kDa}$ categories. After being treated by Fenton process, TOC content of the organic compounds with MWs larger than $1 \mathrm{kDa}$ was eliminated. Meanwhile, the fraction with MW less than $1 \mathrm{kDa}$ greatly removed. The result of MDEL-Fenton process confirmed that the components with large MW are transformed into small ones and higher degree of mineralization of the refractory matters was achieved by MDEL-Fenton oxidation.

Figure $7(\mathrm{~b})$ shows the distribution of $\mathrm{UV}_{254}$ absorbance among the MW based fractions in the leachate, Fenton, and MDEL-Fenton treated leachates under optimized conditions of reagent molar ratios. $\mathrm{UV}_{254}$ quenching substances are considered to be more biologically refractory than TOC in leachates [23]. Similar to TOC fractions in Figure 5(a), $\mathrm{UV}_{254}$ absorbance of the component less than $1 \mathrm{kDa}$ was around $50 \%$ of the overall $\mathrm{UV}_{254}$ of the biologically treated leachate, and the distribution of $\mathrm{UV}_{254}$ quenching substances was relatively even among $\mathrm{MW}>1 \mathrm{kDa}$. It could be observed that $77 \%$ and $96 \%$ of the $\mathrm{UV}_{254}$ quenching substances $>1 \mathrm{kDa}$ got removed after Fenton and MDELFenton oxidation, respectively. For $\mathrm{UV}_{254}$ quenching substances $<1 \mathrm{kDa}$, removal efficiencies of $49 \%$ and $88 \%$ were observed for the Fenton and MDEL-Fenton treated samples. This shows that Fenton's reagents not only mainly target the larger MW $(>1 \mathrm{kDa})$ fractions but also exhibit good removal for $\mathrm{UV}_{254}$ quenching substances $<1 \mathrm{kDa}$. In comparison to Fenton process, the MDEL significantly improved the degradation of $\mathrm{UV}_{254}$ quenching substances with different MWs.

Figure 7(c) shows the changes of color absorbance at $436 \mathrm{~nm}, \mathrm{CO}_{436}$, of different MW fractions in leachate before and after Fenton and MDEL-Fenton oxidation. In the biologically treated leachate, the fraction of substances $>10 \mathrm{kDa}$ contributed more than $30 \%$ of the overall $\mathrm{CO}_{436}$ absorbance, in spite of its $15 \%$ contribution to TOC value. Fenton process effectively removed $\mathrm{CO}_{436}$ absorbance from the refractory matters $>5 \mathrm{kDa}$, while MDEL-Fenton process reduced $\mathrm{CO}_{436}$ absorbance from all MW ranges and an overall color removal efficiency of $91 \%$ was obtained. 


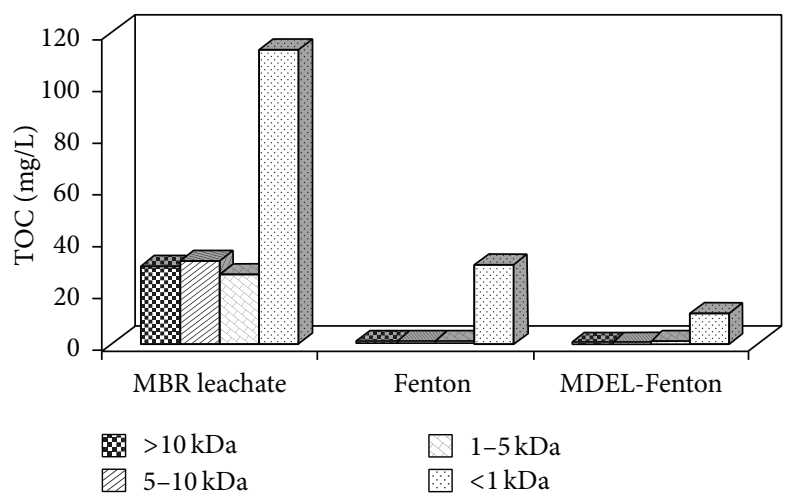

(a)

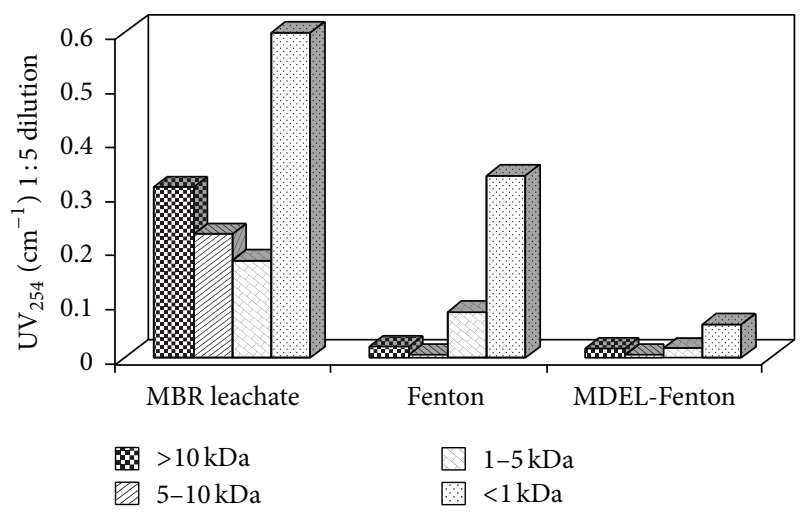

(b)

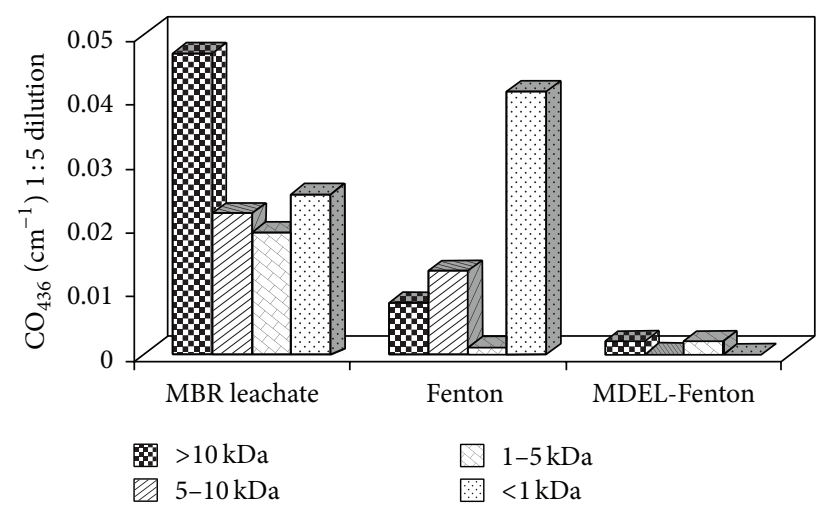

(c)

FIgURE 7: Changes of TOC, $\mathrm{UV}_{254}$, and $\mathrm{CO}_{436}$ absorbance of the effluents in various molecular weight ranges from biologically treated leachate, Fenton, and microwave discharge electrodeless lamp assisted Fenton (MDEL-Fenton) processes.

3.3. Evaluation of MDEL-Fenton Process for Leachate Treatment. Figure 8 presents the contribution of MDEL photolysis, oxidant agents, and Fenton reaction to overall refractory matter removal in terms of COD, TOC, $\mathrm{UV}_{254}$, and $\mathrm{CO}_{436}$. MDEL photolysis resulted in 15\% COD removal and $12 \%$ TOC abatement, while only $3 \% \mathrm{UV}_{254}$ absorbance was reduced from the biologically treated leachate. However, $25 \%$ reduction in $\mathrm{CO}_{436}$ absorbance was observed with MDEL radiations. The addition of ferrous ion led to roughly 5$10 \%$ improvements in COD and TOC removal, while $\mathrm{UV}_{254}$ absorbance decreased significantly to $33 \%$, which implies the transformation of dissolved aromatic carbon content in the leachate. The combination of MDEL and $\mathrm{H}_{2} \mathrm{O}_{2}$ greatly enhanced removal of $\mathrm{UV}_{254}$ and $\mathrm{CO}_{436}$ absorbance to $93 \%$ and $86 \%$, respectively. However, the mineralization of refractory compounds did not increase dramatically, with the COD and TOC removal being $46 \%$ and $52 \%$, respectively. MDEL assisted Fenton process strongly mineralized the refractory organic matter in leachate. Removal efficiencies of $85 \%$ for COD, $89 \%$ for TOC, and $93 \%$ for both $\mathrm{UV}_{254}$ and $\mathrm{CO}_{436}$ absorbance were obtained by MDEL-Fenton process.

3.4. Removal of Trace Polycyclic Aromatic Hydrocarbons by Different Processes. Ten different PAHs were detected in biologically treated leachate samples (Table 2), and the total

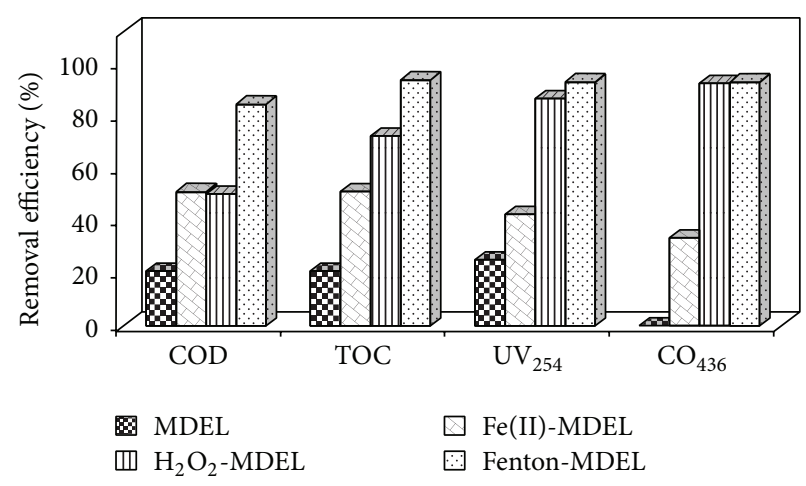

FIGURE 8: Contribution of microwave discharge electrodeless lamp (MDEL) photolysis, oxidant reagents, and Fenton reaction to overall refractory matter removal in MDEL-Fenton treatment.

PAH concentration (i.e., the sum of all $10 \mathrm{PAHs}$ ) is $15.19 \mu \mathrm{g} / \mathrm{L}$. These PAHs contain two to four fused aromatic rings, with those with three rings predominating $(>85 \%)$. The overall $\mathrm{PAH}$ removal efficiencies of $91.9 \%, 94.3 \%$, and $97.9 \%$ were achieved by conventional Fenton, UV-Fenton, and MDELFenton processes, respectively. The total PAH concentrations ranged from 0.31 to $1.23 \mu \mathrm{g} / \mathrm{L}$ in the effluents after the treatment methods used in this study. Conventional Fenton obtained $93 \%$ removal for the PAHs containing three 
TABLE 2: Concentrations of polycyclic aromatic hydrocarbons in biologically treated landfill leachate and after different Fenton-based treatments $\left(\mu \mathrm{g} \mathrm{L}^{-1}\right)$.

\begin{tabular}{|c|c|c|c|c|c|}
\hline Polycyclic aromatic hydrocarbons & Structure & Raw leachate & Fenton & UV-Fenton & MDEL-Fenton \\
\hline 2-Vinylnaphthalene & & $0.55 \pm 0.24$ & $0.10 \pm 0.04$ & $0.03 \pm 0.01$ & N.D. \\
\hline Naphthalene & & $0.41 \pm 0.15$ & $0.26 \pm 0.16$ & $0.14 \pm 0.01$ & $0.05 \pm 0.02$ \\
\hline 1-Methylphenanthrene & & $0.16 \pm 0.03$ & $0.09 \pm 0.04$ & $0.06 \pm 0.01$ & N.D. \\
\hline Acenaphthylene & & $0.19 \pm 0.07$ & $0.10 \pm 0.04$ & $0.09 \pm 0.04$ & $0.05 \pm 0.02$ \\
\hline Acenaphthene & & $4.78 \pm 1.23$ & $0.17 \pm 0.07$ & $0.16 \pm 0.11$ & $0.10 \pm 0.03$ \\
\hline Fluorene & & $4.62 \pm 1.43$ & $0.19 \pm 0.04$ & $0.09 \pm 0.04$ & $0.06 \pm 0.02$ \\
\hline Phenanthrene & & $0.24 \pm 0.13$ & N.D. & N.D. & N.D. \\
\hline Anthracene & & $3.29 \pm 0.16$ & $0.27 \pm 0.07$ & $0.19 \pm 0.05$ & $0.05 \pm 0.02$ \\
\hline Fluoranthene & & $0.84 \pm 0.13$ & $0.05 \pm 0.01$ & $0.11 \pm 0.03$ & N.D. \\
\hline 1-Methylpyrene & & $0.11 \pm 0.05$ & N.D. & N.D. & N.D. \\
\hline
\end{tabular}

rings, while the removal efficiencies for two and four rings were comparatively low, which might result from the low concentration for those PAHs in biologically treated leachate. MDEL assisted Fenton process, nevertheless, significantly enhanced the destruction of these trace amounts of PAHs. Half of the ten different PAHs present in leachate samples are undetectable, and the remaining $\mathrm{PAH}$ concentrations are less than $0.10 \mu \mathrm{g} / \mathrm{L}$. Previous studies reported that PAHs usually complex with the humic substances in different water and wastewater $[24,25]$. Excellent TOC removal in the biologically treated leachates by MDEL-Fenton process probably contributed to the PAHs reduction performance.

\section{Conclusion}

Both Fenton and MDEL-Fenton processes effectively removed the nonbiodegradable organic matters present in the landfill leachate. More than 70\% COD removal could be obtained by Fenton oxidation at the optimal condition of initial $\mathrm{pH} 5.0,2 \mathrm{mM}$ ferrous ion, and $6 \mathrm{mM}$ hydrogen peroxide addition. The introduction of microwave discharge electrodeless lamp could improve the Fenton oxidation to achieve an effluent COD concentration less than $100 \mathrm{mg} \mathrm{L}^{-1}$. Molecular weight distribution assay demonstrates that most large molecular weight $(>1 \mathrm{kDa})$ refractory organic compounds were transformed into organic matters less 
than $1 \mathrm{kDa}$. Ten different polycyclic aromatic hydrocarbons were detected in the leachate samples, $97.9 \%$ of which were removed by MDEL-Fenton process. The combination of MDEL and Fenton provides a single-step polishing process for the refractory organic matters in biologically treated landfill leachate to meet the stringent discharge limit.

\section{Conflict of Interests}

The authors declare that there is no conflict of interests regarding the publication of this paper.

\section{Acknowledgments}

This work was supported by the key project in the Chinese National Science and Technology Pillar Program during the twelfth five-year plan periods (2014BAC12B03), Fundamental Research Funds for the Central Universities in Beijing Jiaotong University (C15JB00040), and National Science Foundation of China (51578042). Y. He, M. Liu, and Y. Liu are acknowledged for analyzing wastewater quality.

\section{References}

[1] H. D. Robinson and P. J. Maris, "The treatment of leachates from domestic waste in landfill sites," Journal of the Water Pollution Control Federation, vol. 57, no. 1, pp. 30-38, 1985.

[2] J. M. Lema, R. Mendez, and R. Blazquez, "Characteristics of landfill leachates and alternatives for their treatment: a review," Water, Air, and Soil Pollution, vol. 40, no. 3-4, pp. 223-250, 1988.

[3] M. Åkesson and P. Nilsson, "Seasonal changes of leachate production and quality from test cells," Journal of Environmental Engineering, vol. 123, no. 9, pp. 892-900, 1997.

[4] A. Baun, A. Ledin, L. A. Reitzel, P. L. Bjerg, and T. H. Christensen, "Xenobiotic organic compounds in leachates from ten Danish MSW landfills-chemical analysis and toxicity tests," Water Research, vol. 38, no. 18, pp. 3845-3858, 2004.

[5] S. Renou, J. G. Givaudan, S. Poulain, F. Dirassouyan, and P. Moulin, "Landfill leachate treatment: review and opportunity," Journal of Hazardous Materials, vol. 150, no. 3, pp. 468-493, 2008.

[6] T. Eggen, M. Moeder, and A. Arukwe, "Municipal landfill leachates: a significant source for new and emerging pollutants," Science of the Total Environment, vol. 408, no. 21, pp. 5147-5157, 2010.

[7] H. Zhang, H. J. Choi, and C.-P. Huang, "Optimization of Fenton process for the treatment of landfill leachate," Journal of Hazardous Materials, vol. 125, no. 1-3, pp. 166-174, 2005.

[8] N. Calace, A. Liberatori, B. M. Petronio, and M. Pietroletti, "Characteristics of different molecular weight fractions of organic matter in landfill leachate and their role in soil sorption of heavy metals," Environmental Pollution, vol. 113, no. 3, pp. 331339, 2001.

[9] I. W. C. Lau, P. Wang, and H. H. P. Fang, "Organic removal of anaerobically treated leachate by Fenton coagulation," Journal of Environmental Engineering, vol. 127, no. 7, pp. 666-669, 2001.

[10] H. Guisen and M. Turan, "Treatment of sanitary Landfill leachate using a combined anaerobic fluidized bed reactor and Fenton's oxidation," Environmental Engineering Science, vol. 21, no. 5, pp. 627-636, 2004.
[11] D. Hermosilla, M. Cortijo, and C. P. Huang, "Optimizing the treatment of landfill leachate by conventional Fenton and photo-Fenton processes," Science of the Total Environment, vol. 407, no. 11, pp. 3473-3481, 2009.

[12] S.-M. Kim, S.-U. Geissen, and A. Vogelpohl, "Landfill leachate treatment by a photo assisted Fenton reaction," Water Science and Technology, vol. 35, no. 4, pp. 239-248, 1997.

[13] S. Horikoshi, M. Kajitani, N. Horikoshi, R. Dillert, and D. W. Bahnemann, "Use of microwave discharge electrodeless lamps (MDEL): II. Photodegradation of acetaldehyde over $\mathrm{TiO}_{2}$ pellets," Journal of Photochemistry and Photobiology A: Chemistry, vol. 193, no. 2-3, pp. 284-287, 2008.

[14] S. Horikoshi, M. Kajitani, S. Sato, and N. Serpone, "A novel environmental risk-free microwave discharge electrodeless lamp (MDEL) in advanced oxidation processes: degradation of the 2,4-D herbicide," Journal of Photochemistry and Photobiology A: Chemistry, vol. 189, no. 2-3, pp. 355-363, 2007.

[15] Y. Ju, J. Fang, X. Liu et al., "Photodegradation of crystal violet in $\mathrm{TiO}_{2}$ suspensions using UV-vis irradiation from two microwave-powered electrodeless discharge lamps (EDL-2): products, mechanism and feasibility," Journal of Hazardous Materials, vol. 185, no. 2-3, pp. 1489-1498, 2011.

[16] Y. Yu, T. Zhang, L. Zheng, and J. Yu, "Photocatalytic degradation of hydrogen sulfide using $\mathrm{TiO}_{2}$ film under microwave electrodeless discharge lamp irradiation," Chemical Engineering Journal, vol. 225, pp. 9-15, 2013.

[17] D. Qu, Z. Qiang, S. Xiao, Q. Liu, Y. Lei, and T. Zhou, "Degradation of Reactive Black 5 in a submerged photocatalytic membrane distillation reactor with microwave electrodeless lamps as light source," Separation and Purification Technology, vol. 122, pp. 54-59, 2014.

[18] P. Klán, J. Literák, and M. Hájek, “The electrodeless discharge lamp: a prospective tool for photochemistry," Journal of Photochemistry and Photobiology A: Chemistry, vol. 128, no. 1-3, pp. 145-149, 1999.

[19] P. Klán, M. Hájek, and V. Církva, “The electrodeless discharge lamp: a prospective tool for photochemistry: part 3. The microwave photochemistry reactor," Journal of Photochemistry and Photobiology A: Chemistry, vol. 140, no. 3, pp. 185-189, 2001.

[20] E. P. A. Sino, Chinese Standard Methods for the Examination of Water and Wastewater, Chinese Environmental Science, 2002.

[21] F. Harber and J. J. Weiss, "The catalytic decomposition of hydrogen peroxide by iron salts," Journal of the American Chemical Society, vol. 45, pp. 338-351, 1934.

[22] S. Kim and A. Vogelpohl, "Degradation of organic pollutants by photo-Fenton," Chemical Engineering \& Technology, vol. 21, pp. 187-191, 1998.

[23] R. Zhao, A. Gupta, J. T. Novak, C. D. Goldsmith, and N. Driskill, "Characterization and treatment of organic constituents in landfill leachates that influence the UV disinfection in the publicly owned treatment works (POTWs)," Journal of Hazardous Materials, vol. 258-259, pp. 1-9, 2013.

[24] P.-J. He, J.-F. Xue, L.-M. Shao, G.-J. Li, and D.-J. Lee, "Dissolved organic matter (DOM) in recycled leachate of bioreactor landfill," Water Research, vol. 40, no. 7, pp. 1465-1473, 2006.

[25] K. G. Villholth, "Colloid characterization and colloidal phase partitioning of polycyclic aromatic hydrocarbons in two creosote-contaminated aquifers in Denmark," Environmental Science and Technology, vol. 33, no. 5, pp. 691-699, 1999. 

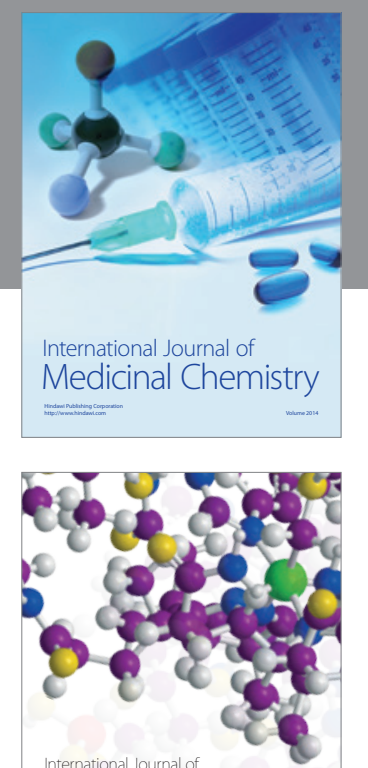

\section{Carbohydrate} Chemistry

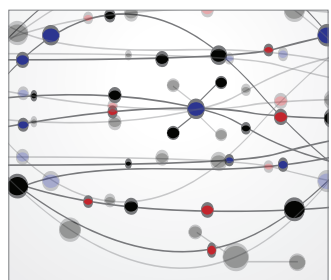

The Scientific World Journal
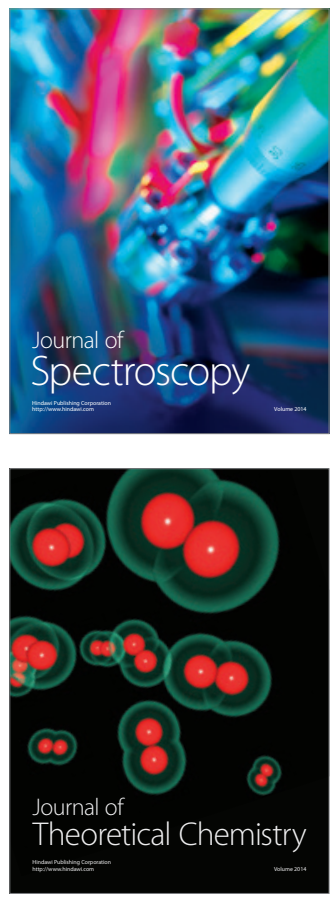
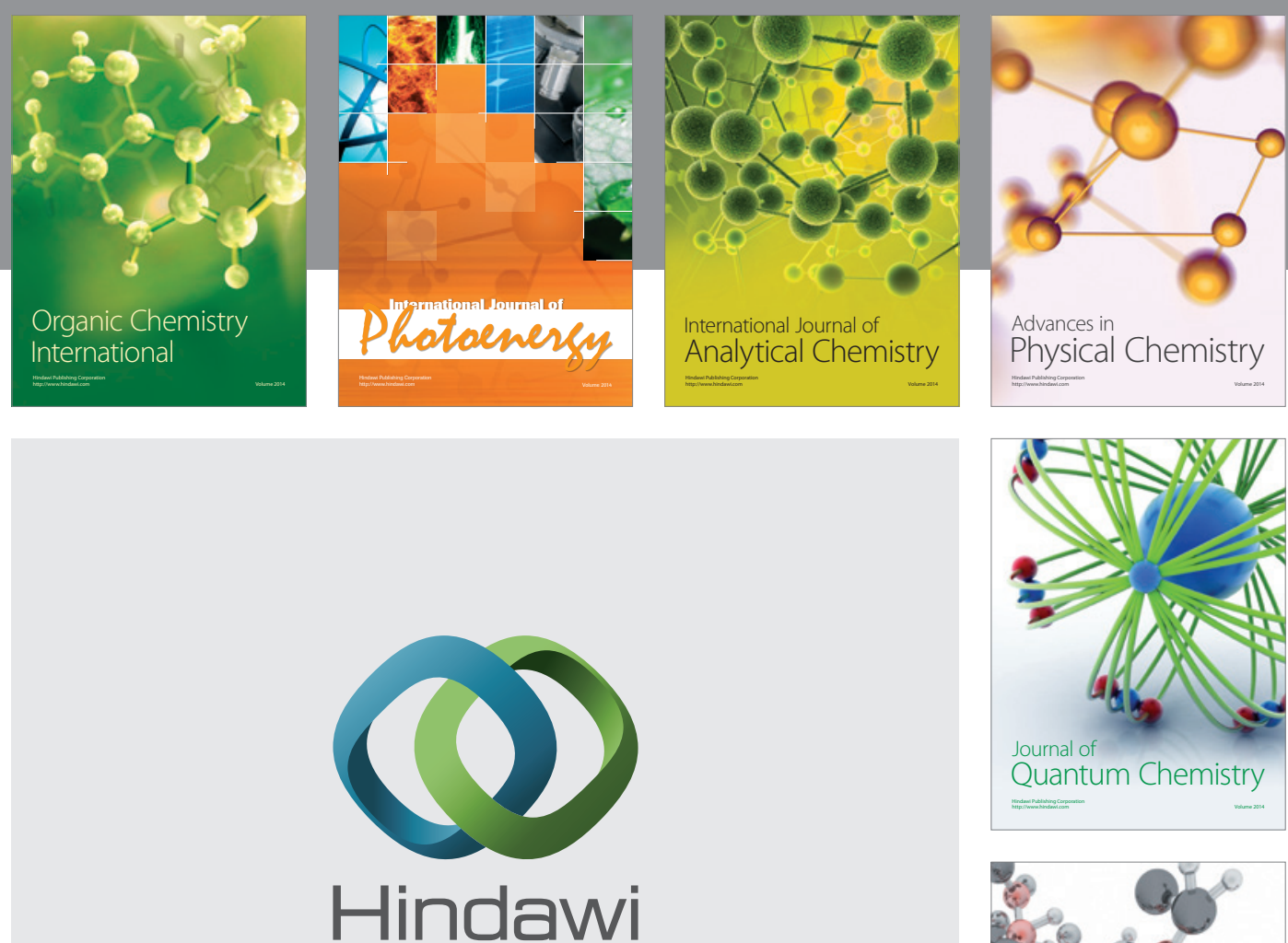

Submit your manuscripts at

http://www.hindawi.com

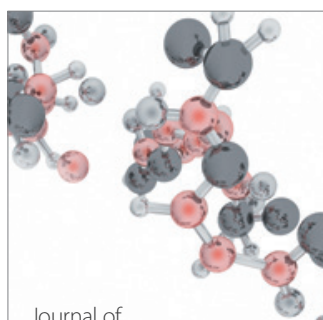

Analytical Methods

in Chemistry

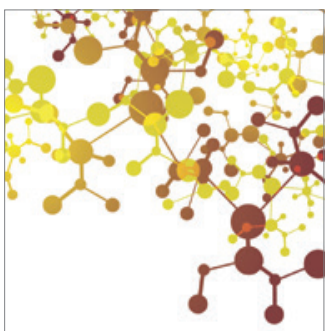

Journal of

Applied Chemistry

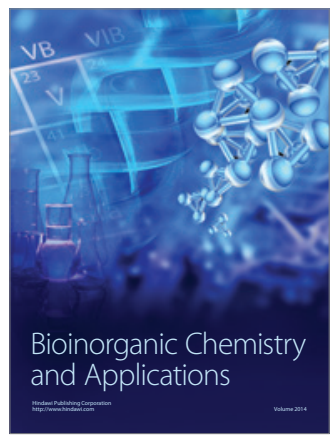

Inorganic Chemistry
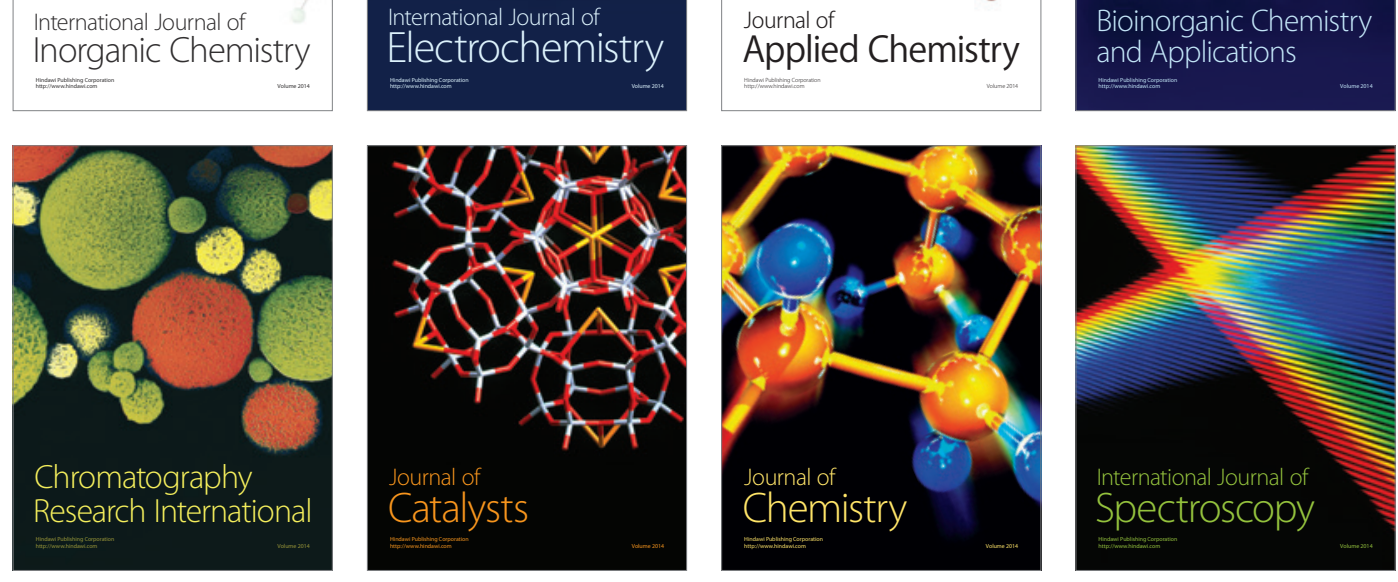